\title{
Transmisión vertical del virus de la inmunodeficiencia humana en mujeres usuarias del Centro Hospitalario Pereira Rossell; Uruguay, 2012-2014. Resultados de la aplicación del protocolo zidovudina - nevirapina en niños uruguayos
}

\author{
Dras. Ana Virginia González Castro*, Stella Inés Gutiérrez Rodríguez†, Ana Visconti Gazano¥ \\ Centro Nacional de Referencia Obstétrico - Pediátrico VIH-Sida del Centro Hospitalario Pereira Rossell.
}

\section{Resumen}

Introducción: el embarazo controlado y la supresión del amamantamiento son estrategias para disminuir la transmisión vertical (TMI) del virus de inmunodeficiencia humana (VIH). La profilaxis al neonato con zidovudina o zidovudina con nevirapina se utiliza según el riesgo de TMI.

Objetivo: describir la TMI entre los años 2012 y 2014 en el Centro Hospitalario Pereira Rossell (CHPR), su relación con la carga viral materna y el cumplimiento de la recomendación AZT-NVP al neonato.

Material y método: estudio descriptivo en el Centro de Referencia Obstétrico - Pediátrico VIH-Sida desde $1^{\circ}$ de setiembre de 2012 al 31 de diciembre 2014. Se incluyeron los recién nacidos de mujeres con carga viral detectable o indetectable al momento del parto. Se registró la administración de zidovudina-nevirapina. Se determinó la transmisión vertical.

Resultados: se incluyeron 162 mujeres, 86 con carga viral detectable o desconocida y 76 indetectable. Las primeras tuvieron 88 hijos y las segundas 76. La TMl global fue de 4,9\%; $9 \%$ en el primer grupo y 0\% en el segundo. Se registró asociación entre TMI y CV materna ( $p<0,05)$. La administración de AZT-NVP se indicó en 46,5\% de los niños. De los ocho niños infectados, la TMI fue intraútero en cinco. En los tres restantes, dos recibieron AZT y otro ninguna profilaxis.

Discusión y conclusiones: la mitad de las mujeres no controló bien su embarazo. La TMl promedio fue de 4,9\%. De los ocho infectados, cinco fueron intraútero; solo un diagnóstico y tratamiento precoces lo hubiesen evitado. El protocolo AZT-NVP no se utiliza en forma adecuada. Quizá su aplicación en los tres niños restantes hubiera evitado la infección.

Palabras clave: TRANSMISIÓN VERTICAL DE ENFERMEDAD INFECCIOSA

$\mathrm{VIH}$

NEVIRAPINA

Key words: $\quad$ VERTICAL INFECTIOUS DISEASE TRANSMISSION

HIV

NEVIPARINE

\footnotetext{
* Profesora Adjunta de Pediatría. Facultad de Medicina - Universidad de la República. Pediatra del Centro Nacional de Referencia Obstétrico Pediátrico VIH-SIDA del Centro Hospitalario Pereira Rossell.

† Profesora Agregada de Pediatría. Facultad de Medicina - Universidad de la República. Directora del Centro Nacional de Referencia Obstétrico Pediátrico VIH-SIDA del Centro Hospitalario Pereira Rossell.

‡ Ginecóloga del Centro Nacional de Referencia Obstétrico - Pediátrico VIH-SIDA del Centro Hospitalario Pereira Rossell.

Correspondencia: Virginia González. Maldonado M 11 S 13. Solymar, Canelones. Correo electrónico: vickygc21@gmail.com

Los autores declaran no tener conflicto de intereses.

Este trabajo ha sido aprobado por el Comité de Ética en Investigación del Centro Hospitalario Pereira Rossell.

Recibido: $9 / 5 / 17$

Aprobado: 13/11/17
} 


\section{Introducción}

El adecuado control del embarazo, el uso de terapia antirretroviral (TARV), la elección de la vía de nacimiento y la supresión de la lactancia materna son las estrategias más importantes para disminuir la transmisión materno infantil (TMI) del virus de inmunodeficiencia humana $(\mathrm{VIH})^{(1-7)}$.

En el año 1994, Connor y colaboradores demostraron que la administración de zidovudina (AZT) a gestantes infectadas por el VIH asintomáticas durante el embarazo, parto y al recién nacido era capaz de reducir la TMI de $30 \%$ a $8 \%$ en niños no amamantados ${ }^{(1)}$.

En el año 2002 se logró reducir la transmisión a 1\%-2\% mediante la administración de tres o más antirretrovirales (ARV) a la mujer embarazada (tratamiento de alta eficacia, TAE) ${ }^{(2-4)}$.

Townsend y colaboradores en el año 2008 describieron una tasa global de TMI de 1,2\%. Pero dentro de este grupo, la tasa era $0,1 \%$ en niños no amamantados, hijos de mujeres que recibieron TAE y cuya carga viral era indetectable al momento del parto ${ }^{(8)}$.

Posteriormente se demostró que el nacimiento del niño por cesárea coordinada solo disminuía la transmisión intraparto en las mujeres que llegaban a ese momento con una carga viral detectable ( $>50$ copias $/ \mathrm{ml})^{(5-8)}$.

Actualmente los objetivos principales de la TARV en la mujer embarazada son suprimir la carga viral materna para evitar la transmisión vertical (TV) y la aparición de resistencia a los ARV que limiten futuras intervenciones terapéuticas preservando la salud materna y del niño ${ }^{(6,7,9)}$.

La TMI es más frecuente en el momento del parto. La búsqueda del virus mediante reacción en cadena de la polimerasa (PCR) en las primeras 48 horas de nacido puede ser positiva cuando la infección se adquirió intraútero, pero es negativa cuando fue perinatal. En estos casos, el diagnóstico se realiza entre los 15 días y los 5 meses de vida ${ }^{(7-9,11)}$. Del total de partos asistidos o derivados al Centro Hospitalario Pereira Rossell (CHPR) entre los años 2009 y 2013, el $32,6 \%$ provenía de embarazos mal controlados o no controlados ${ }^{(10)}$.

De los nacimientos en el CHPR en ese mismo período, la infección materna por VIH presentó una tasa entre 7,2 y $9,2 / 1.000$ nacidos $^{(10)}$.

En Uruguay se ofrece la prueba de VIH a la mujer embarazada en la primera consulta y en el segundo y tercer trimestre del embarazo. En caso que la mujer conozca previamente su infección y esté en TARV con carga viral (CV) indetectable, el tratamiento se mantiene sin cambios; con CV detectable, se valora adherencia y se solicita test de resistencia y de ser necesario se cambia plan ARV sin esperar los resultados ajustándose poste- riormente. Si la infección se diagnostica durante los controles, inicia el plan con AZT, lamivudina (3TC), lopinavir/ritonavir u otros, entre la semana 12 y 14 de gestación. De ser posible se utiliza un plan que contenga $\mathrm{AZT}$. La vía de nacimiento dependerá de la CV materna al final del embarazo: si es indetectable se ofrece el parto a la mujer, si es detectable o desconocida se realiza cesárea. En todos los casos se administra una dosis carga de AZT intravenosa durante el trabajo de parto y luego dosis de mantenimiento hasta el clampeo del cordón umbilical. En algunos casos de diagnóstico tardío, puede asociarse una dosis de nevirapina dos horas o más previo al parto o cesárea. Luego de nacido el niño, se inhibe la lactancia y se administran fórmulas de sustitución para su alimentación ${ }^{(6,7,9,17,18)}$.

Las mujeres que llegan al momento del parto con una carga viral detectable o desconocida por mal control del embarazo tienen mayor riesgo de transmisión al recién nacido.

En Uruguay, la TMI alcanzó cifras de 2,9\% en el año $2014^{(11)}$.

El régimen seleccionado de profilaxis con ARV al neonato depende del riesgo teórico de transmisión vertical teniendo en cuenta la carga viral materna previa al parto $^{(6-8)}$.

Gray y colaboradores en 2005 describieron que el riesgo de transmisión intraparto disminuye en mujeres sin tratamiento cuyos recién nacidos recibieron nevirapina en dosis única vía oral ${ }^{(12)}$.

Nielsen-Saines en el año 2012 demostró que la administración de zidovudina por seis semanas con tres dosis de nevirapina o la administración de zidovudina, lamivudina y nelfinavir por 15 días a recién nacidos, hijos de mujeres sin tratamiento antirretroviral en el embarazo o parto fue más eficaz que la zidovudina sola para reducir la transmisión intraparto del VIH al niño $(2,2 \%, 2,4 \%$ y $4,8 \%$, respectivamente, $p=0,046$ ). Como los efectos adversos fueron más frecuentes con tres fármacos, la elección de zidovudina con nevirapina comenzó a utilizarse en los casos de mal control del embarazo ${ }^{(13,16)}$.

En Uruguay, la zidovudina con nevirapina comenzó a utilizarse en setiembre de 2012 como profilaxis de infección al recién nacido hijo de una mujer infectada que no controló su embarazo o que llegó al momento del parto con carga viral desconocida o mayor a 1000 copias $/ \mathrm{ml}$. Luego la recomendación se extendió a los hijos de mujeres con carga viral detectable (> 50 copias $/ \mathrm{ml}$ ). $\mathrm{Al}$ inicio, la disponibilidad de la nevirapina suspensión fue escasa y solo algunos niños en el CHPR pudieron recibirla. En los años 2013 y 2014 su uso se generalizó a todos los niños nacidos en maternidades públicas y privadas. 
El tratamiento incluía AZT a $4 \mathrm{mg} / \mathrm{kg}$ vía oral cada $12 \mathrm{~h}$ durante 42 días en los niños $\geq$ de 35 semanas de edad gestacional $(<35$ semanas a $2 \mathrm{mg} / \mathrm{kg}$ cada $12 \mathrm{~h})$ más tres dosis de NVP a $12 \mathrm{mg}$ vía oral en los niños $>2$ $\mathrm{kg}$ de peso ( $8 \mathrm{mg}$ entre $1,5-2 \mathrm{~kg}$ ) en los 7-8 primeros días de vida (primera dosis al nacer, segunda dosis a los dos días de la primera y la tercera dosis a los cuatro días de la segunda).

$\mathrm{Si}$ a pesar del tratamiento preventivo el niño se infecta, la resistencia que pueda aparecer a la nevirapina no influirá en el tratamiento, ya que el tratamiento de alta eficacia recomendado en esa etapa incluye inhibidores de la proteasa (IP) y no nevirapina como fármacos de primera línea $^{(7,17,18)}$.

Es importante conocer los primeros resultados de la difusión del nuevo protocolo de tratamiento preventivo neonatal para los recién nacidos hijos de mujeres con mal control del embarazo y carga viral detectable o desconocida.

Los objetivos del siguiente trabajo fueron describir a partir del año 2012 en la maternidad del CHPR:

1. La TMI en niños y su relación con la carga viral materna.

2. Las características clínico-epidemiológicas más importantes de las mujeres infectadas.

3. El cumplimiento de la recomendación AZT-NVP para el recién nacido hijo de una mujer con carga viral detectable o desconocida y su beneficio en la TMI.

4. La aparición de resistencia a la nevirapina en caso de infección.

\section{Material y método}

Se realizó un estudio descriptivo, observacional, en el Centro de Referencia Obstétrico - Pediátrico VIH-SIDA del CHPR desde el $1^{\circ}$ de setiembre de 2012 al 31 de diciembre de 2014.

Se incluyeron todos los recién nacidos de mujeres con carga viral detectable o desconocida (grupo 1) y carga viral indetectable (grupo 2) al momento del parto. En el primer grupo se registró si había recibido zidovudina con nevirapina o exclusivamente zidovudina. Se determinó la transmisión vertical en cada uno de ellos.

La fuente primaria de datos fue el registro de las historias clínicas obstétricas y pediátricas del centro. La extracción de datos se realizó manteniendo la confidencialidad de los mismos.

El estudio fue aprobado por el Comité de Ética del Hospital Pediátrico del CHPR.

Las variables estudiadas fueron maternas y del niño. De las primeras, edad, diagnóstico de infección por VIH previo al embarazo, tratamiento farmacológico utiliza- do previo al embarazo y durante el mismo, edad gestacional al inicio del tratamiento, realización y resultado de test de resistencia, CV previa al parto, uso de nevirapina como dosis única previa al parto, zidovudina intravenosa y vía de nacimiento. Del niño, amamantamiento, indicación de zidovudina más nevirapina o zidovudina en forma exclusiva, momento del diagnóstico en caso de infección y resultado de test de resistencia.

Se definió infección intraparto cuando el resultado de la PCR ADN proviral en las primeras 48 horas del nacimiento del recién nacido fue negativo y las siguientes del primer y/o cuarto mes positivas; infección intraútero, la primera PCR positiva en los primeros días de vida.

Se utilizaron medianas como medida de tendencia central y porcentajes con su respectivo intervalo de confianza del 95\%. Se utilizó el test de chi cuadrado para comparar ambos grupos.

\section{Resultados}

En el período de estudio, 162 mujeres infectadas con VIH tuvieron su parto o cesárea en el CHPR; 86 (53\%) con carga viral detectable o desconocida y $76(47 \%)$ con carga viral indetectable al momento del nacimiento. Las primeras tuvieron 88 hijos (dos embarazos gemelares) y las segundas, 76 .

La TMI global en ese período fue de 4,9\%. Al desglosarla por grupos, la TMI fue 9\% (IC95\%, 4-18\%) (8 niños) en el grupo de mujeres con carga viral detectable o desconocida y 0 (IC 95\%, 0-6\%) en el grupo de mujeres con carga viral indetectable. De los ocho niños infectados, tres se infectaron en el año 2012, dos en 2013 y tres en 2014. En ese período se registró asociación entre la TMI y la CV materna $(\mathrm{p}<0,05)$.

La administración de AZT en el parto o cesárea y la supresión de la lactancia materna fueron similares en ambos grupos. Sin embargo, las mujeres con carga viral indetectable eran de mayor edad, conocían más el diagnóstico de infección previo al embarazo, recibieron TARV durante todo el embarazo y presentaron menor cesárea electiva $(\mathrm{p}<0,05)$. Los resultados se muestran en la tabla 1.

De las 86 mujeres con carga viral detectable o desconocida, 37 (43\%) conocían su infección previo al embarazo y $49(57 \%)$ lo conocieron en el embarazo.

De las 49 mujeres, 37 se diagnosticaron durante la gestación, diez en el momento del parto o cesárea y dos se diagnosticaron en el puerperio.

La TARV recibida en el 70\% fue AZT, 3TC y lopinavir/ritonavir.

En este grupo se realizó test de resistencia a seis mujeres: cinco no tuvieron mutaciones de resistencia y una, posible resistencia a un inhibidor de la proteasa. El valor de la carga viral previo al parto se obtuvo en 58 casos. El 
Tabla 1. Características de las mujeres según resultado de carga viral al momento del nacimiento.

\begin{tabular}{|c|c|c|c|}
\hline & $\begin{array}{c}\text { Mujeres con CV detectable o } \\
\text { desconocida } \\
N=86\end{array}$ & $\begin{array}{l}\text { Mujeres con CV indetectable } \\
\qquad N=76\end{array}$ & \\
\hline Mediana de edad (rango) & 24 años (16 - 42) & 29 años (16 - 44) & $p<0,05$ \\
\hline \multirow{4}{*}{$\begin{array}{l}\text { Momento del diagnóstico de infección } \\
\text { por VIH }\end{array}$} & Previo al embarazo & $37(43 \%)$ & $56(73,7 \%)$ \\
\hline & Durante embarazo & $37(43 \%)$ & $20(26,3 \%)$ \\
\hline & Parto/cesárea & $10(11,7 \%)$ & 0 \\
\hline & Puerperio & $2(2,3 \%)$ & 0 \\
\hline \multirow[t]{5}{*}{ Profilaxis TMI } & TARV durante embarazo & $61(71 \%)$ & $76(100 \%)$ \\
\hline & AZT i/v durante parto/cesárea & $70(81,4 \%)$ & $66(86,8 \%)$ \\
\hline & $\begin{array}{c}1 \text { dosis de nevirapina v/o previo al } \\
\text { parto/cesárea }\end{array}$ & $10(11,6 \%)$ & $\begin{array}{c}1(1,3 \%) \\
\text { (no corresponde) }\end{array}$ \\
\hline & Cesárea electiva & $45(52 \%)$ & $17(22,4 \%)$ \\
\hline & Supresión de la lactancia & $82(95 \%)$ & $76(100 \%)$ \\
\hline $\begin{array}{l}\text { Mediana de edad gestacional y rango } \\
\text { al inicio de TARV (sem) }\end{array}$ & $26 \operatorname{sem}(9-37)$ & $17 \operatorname{sem}(12-33)$ & $p<0,05$ \\
\hline TARV durante todo el embarazo & $6(7 \%)$ & $28(36,8 \%)$ & $p<0,05$ \\
\hline Transmisión vertical & $9 \%$ & $0 \%$ & $p<0,05$ \\
\hline
\end{tabular}

promedio de copias fue de 3.500 con un rango de 50 a 2.400.000.

De la 76 mujeres con carga viral indetectable, 56 $(73,7 \%)$ conocían su infección previo al embarazo y 20 se diagnosticaron durante el mismo. De las que conocían previamente su diagnóstico (N: 56), 44 recibieron medicación en algún momento y 28 la recibían al momento de embarazarse. En ellas, la TARV recibida en el $81,6 \%$ de los casos fue AZT, 3TC y lopinavir/ritonavir.

Se realizó test de resistencia a siete de las 76 mujeres durante el embarazo, cinco no tuvieron mutaciones de resistencia, una tenía resistencia a algunos inhibidores no nucleosídicos y otra a algunos inhibidores nucleosídicos y no nucleosídicos.

De los 88 recién nacidos cuyas madres desconocían la última CV o esta era detectable, 41 (46,5\%) recibieron NVP-AZT cumpliendo con el protocolo. El resto solo AZT y en dos casos de diagnóstico luego del nacimiento, ningún tratamiento.

De los 88, la TMI fue intraútero en cinco casos. Eliminando estos casos de transmisión intraútero, de los 37 niños que recibieron AZT- NVP, ninguno se infectó y de los 46 que no recibieron este tratamiento, se infectaron tres. La quimioprofilaxis adecuada en este caso no se asoció con la infección del niño $(\mathrm{p}>0,05)$.
De los ocho niños infectados, cuatro nacieron por cesárea coordinada, uno por cesárea de urgencia y tres por parto vaginal. Los resultados se muestran en las tablas 2 y 3 .

La utilización de la NVP a partir de su disponibilidad en Uruguay se muestra en la figura 1.

De los ocho niños infectados, el test de resistencia no presentó mutaciones en seis casos, en uno posible resistencia a inhibidores no nucleosídicos y posible resistencia a algunos inhibidores de la proteasa (tipranavir/ritonavir) y en otro resistencia a inhibidores no nucleosídicos. En estos dos últimos casos la mujer no había recibido antirretrovirales previo al parto. Los resultados se muestran en la tabla 4.

\section{Discusión}

En el año 2010, la Organización Panamericana de la Salud aprobó la Estrategia y plan de acción para la eliminación de la transmisión materno infantil del VIH y de la sífilis congénita. La meta es la reducción de la transmisión materno infantil del $\mathrm{VIH} a \leq 2 \%$ y la incidencia de la transmisión a $\leq 0,3$ caso por cada 1.000 nacidos vi$\operatorname{vos}^{(19)}$.

Desde entonces, al igual que otros países, Uruguay tiene dentro de sus objetivos prioritarios la eliminación 
Tabla 2. Profilaxis y diagnóstico en hijos de madres infectadas con VIH.

\begin{tabular}{lcc}
\hline & Hijos de madres con CV detectable o Hijos de madre con CV indetectable. \\
desconocida. $N=88$ & $N=76$
\end{tabular}

Tabla 3. Diagnóstico de infección y profilaxis recibida en hijos de madre con CV detectable o desconocida.

\begin{tabular}{|c|c|c|c|c|}
\hline & \multicolumn{4}{|c|}{ Hijos de madres con CV detectable o desconocida $N=88$} \\
\hline & \multicolumn{3}{|c|}{ Niños infectados $N=8$} & \multirow[t]{2}{*}{ Niños no infectados $N=80$} \\
\hline & 1er $P C R$ & $2^{a} P C R$ & 3era $P C R$ & \\
\hline$A Z T+N V P$ & 4 & & & $37(46,25 \%)$ \\
\hline AZT & & 2 & & $42(52,5)$ \\
\hline \multirow[t]{2}{*}{ Sin profilaxis } & 1 & & 1 & $1(1,25)$ \\
\hline & 5 & 2 & 1 & 80 \\
\hline
\end{tabular}

de la transmisión vertical del VIH y la sífilis congénita. Para cumplir con estos objetivos, el Ministerio de Salud priorizó la atención integral de la mujer embarazada con especial énfasis en la captación precoz del embarazo e implementó diferentes acciones complementarias y sinérgicas para el período $2010-2015^{(20-21)}$.

Una de las acciones que comenzó en el año 2013 fue la auditoría nacional de VIH donde se analizan los diferentes factores que llevan a que un niño adquiera la infección. A partir de ella, se registró una prevalencia de infección en el embarazo de 0,26\% y de TMI de 1,6\% a nivel nacional en ese año y de 0,29 y 2,9 , respectivamente, en 2014. Los dos casos de TV se vincularon a retardo en el diagnóstico y ausencia de intervenciones para su prevención en el subsector público ${ }^{(11)}$.

Las cifras globales de TMI halladas en este trabajo de 4,9\% entre los años 2012 y 2014 en mujeres usuarias de la Administración de los Servicios de Salud del Estado está por encima de las cifras de los países donde la mujer controla su embarazo y de las cifras nacio- nales de TMI de 1,6\% (2013) y 2,9\% (2014). La mitad de las mujeres involucradas en este estudio no controlaron por alguna razón en forma adecuada su embarazo. Y son estas las que pueden tener niños infectados, como lo que ocurrió en este caso donde de 86 mujeres con mal control nacieron ocho niños infectados y de 76 mujeres con control adecuado y carga viral indetectable, todos los niños fueron sanos. Al observar las diferencias entre los dos grupos, es el conocimiento previo de la infección antes del embarazo y el tratamiento durante el mismo, al igual que ocurre en otros centros, los factores que se asociaron a mujeres con $\mathrm{CV}$ indetectable y niños sanos. En este caso, además, la mayor edad de las mujeres también se asoció a buen control del embarazo y niños sanos.

Con respecto al conocimiento previo de la infección, si bien se asocia generalmente a baja TMI, la relación no siempre existe, ya que otras condicionantes pueden influir en ese contexto. En nuestro caso, el 73,7\% de las mujeres con $\mathrm{CV}$ indetectable conocía previamente su 
Tabla 4. Tratamiento antirretroviral madre - hijo y resistencia en el niño.

\begin{tabular}{|c|c|c|c|c|c|}
\hline & \multicolumn{3}{|c|}{ Madre } & \multicolumn{2}{|c|}{ Recién nacido } \\
\hline & \multirow{2}{*}{$\begin{array}{c}\text { Embarazo } \\
\text { Antirretrovirales }\end{array}$} & \multicolumn{2}{|c|}{ Parto } & \multirow[b]{2}{*}{$A Z T$} & \multirow[b]{2}{*}{$A Z T+N V P$} \\
\hline & & AZT i/v & $A Z T i / v+N V P$ v/o & & \\
\hline $\begin{array}{l}\text { Niño } 1 \\
\text { Posible resistencia a inhibidores no nucleosídicos } \\
\text { y a algunos inhibidores de la proteasa }\end{array}$ & $\begin{array}{l}\text { No recibe } \\
\text { tratamiento* }\end{array}$ & & Sí & Sí & \\
\hline $\begin{array}{l}\text { Niño } 2 \\
\text { Resistencia a inhibidores no nucleosídicos }\end{array}$ & $\begin{array}{l}\text { No recibe } \\
\text { tratamiento* }\end{array}$ & Sí & & & Sí \\
\hline
\end{tabular}

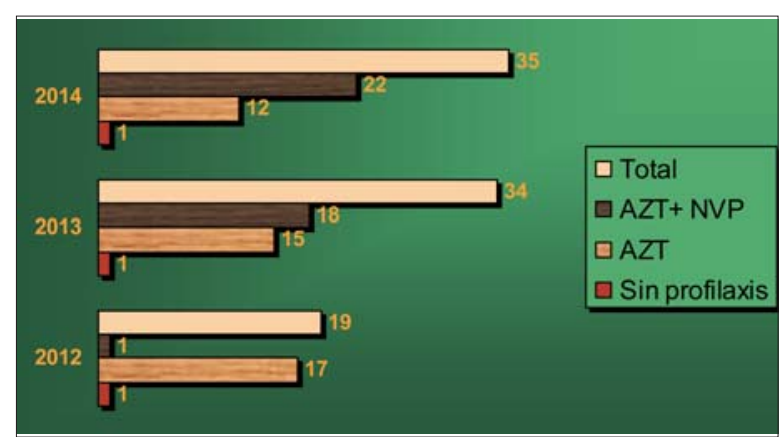

Figura 1. Profilaxis en el recién nacido por año. $N=88$ * * La disponibilidad de NVP en 2012 era exclusiva del CHPR.

enfermedad, pero el $43 \%$ con enfermedad no controlada también la conocía.

En Brasil, donde la prevalencia de infección en la mujer embarazada es $0,38 \%$ superior a la nuestra, la utilización de HAART en el embarazo se incrementó en Río Grande del Sur (segundo lugar de mayor notificación de mujeres embarazadas infectadas de Brasil) a 73,3\% entre los años 2005 y 2011 con cifras de TMI de 2,9\% ${ }^{(22)}$. En un centro de referencia VIH - SIDA de Bahía, la TMI fue de $8,2 \%$ entre los años 2005 y $2008^{(23)}$.

En el estado de Georgia, Estados Unidos, se identificaron 27 niños infectados por VIH por TMI entre los años 2005 y 2012; 20 mujeres conocían previamente su condiciónVIH ${ }^{(24)}$.

La TMI puede producirse in útero en un tercio de los casos, particularmente en el tercer trimestre. La infección progresiva de la placenta alcanza la circulación fetal aunque también se describen rupturas de la barrera placentaria seguidas de microtransfusiones de la madre al hijo ${ }^{(25)}$. Esta situación solo puede evitarse si la mujer planifica su embarazo o controla el mismo de manera precoz para obtener el diagnóstico de infección en caso que no lo supiera y el tratamiento correspondiente.

De los ocho niños infectados en el período, cinco fueron por transmisión intraútero, lo que muestra que más de la mitad de esos niños no se hubiesen beneficiado de las estrategias usadas en el momento del nacimiento para evitar la infección intraparto. Es en estas circunstancias donde el conocimiento previo de la infección puede evitar la TMI. El saber que se tiene la enfermedad lleva al tratamiento y este a la disminución de la TMI.

A partir del año 2014, se recomienda agregar raltegravir en el último mes del embarazo al TARV en las mujeres con diagnóstico tardío de infección y $\mathrm{CV}$ detectable o desconocida ${ }^{(26)}$

El 70\% de la transmisión ocurre a nivel perinatal por el contacto del feto con las secreciones maternas infectadas cuando pasa por el canal de parto o por ascenso de la infección desde la vagina a las membranas fetales y líquido amniótico o por absorción por el tracto digestivo del neonato ${ }^{(26)}$. Es en este escenario donde el test rápido en caso de desconocimiento de la enfermedad, el AZT intravenoso, la utilización de AZT y nevirapina en el neonato que no amamanta serán la gran barrera para evitar la TMI. La infección en tres de los ocho niños infectados ocurrió en el período perinatal. Ninguno de los tres recibió la profilaxis neonatal con AZT y nevirapina: dos solo AZT y uno ninguna profilaxis debido a que el diagnóstico materno se hizo a los 13 días del parto (cuando se recibe el resultado solicitado en el tercer trimestre del embarazo y no se había realizado test rápido). En un país donde la atención y el tratamiento de la infección por VIH son gratuitos es difícil aceptar que no se utilice en forma adecuada el tratamiento neonatal, último pilar que se pone en marcha para evitar la TMI. Los resultados hubieran podido ser peores, ya que el 53\% de los niños, hijos de mujeres con CV desconocida o detectable, tampoco recibieron la pauta que correspondía a ese escenario. 
En el período estudiado la infección del niño adquirida en el período perinatal no se asoció al tratamiento incompleto neonatal. Seguramente un mayor aumento del número de casos hubiera podido mostrar esta asociación.

En Buenos Aires, Argentina, la prevalencia de infección vertical entre los años 2003 y 2008 fue de 6,3\% y los factores asociados fueron la ausencia de profilaxis prenatal, el diagnóstico tardío de infección, el bajo nivel de instrucción materno y el parto vaginal. Sin embargo, en ese mismo período, en un hospital público de complejidad terciaria de esa ciudad (Hospital Dr. Cosme Argerich), la TMI fue de $0,6 \%$ (1 de 164 niños). Los resultados son totalmente diferentes en una misma ciudad. En ese caso, todas las mujeres y neonatos recibieron tratamiento preventivo y el $82,9 \%$ de las mujeres presentaban carga viral $<1000 \mathrm{cp} / \mathrm{ml}$, por lo que no alcanza con tener todas las herramientas disponibles, sino que se debe trabajar para aplicarlas y en caso de situaciones de vulnerabilidad social, el equipo de salud como equipo de trabajo interdisciplinario debe ser más eficiente en la captación y seguimiento de las mujeres y niños apoyado por las redes sociales existentes. En ese centro el equipo de salud interdisciplinario facilita la derivación a cada especialista, el seguimiento adecuado de la gestación minimizando las pérdidas en el seguimiento, agilizando los trámites burocráticos inherentes a la prescripción del tratamiento ARV y a la realización de estudios específi$\cos ^{(27)}$. El equipo de salud logró ese resultado con mucho esfuerzo.

En Uruguay también existe un equipo de salud comprometido que ha logrado llegar a cifras bajas de TMI, pero no son las deseadas como meta a alcanzar, inferiores a $2 \%$. Siguen existiendo mujeres que no controlan o controlan poco su embarazo y existen además fallas en el equipo de salud que no utiliza todos los recursos disponibles en el neonato para evitar su infección. La utilización de AZT-nevirapina en el niño no amamantado desde las primeras horas de vida es un método utilizado por la mayoría de países que no logran descender la TMI a cifras menores de $2 \%$. Es el último recurso del personal de salud, por lo que todas las maternidades deberían monitorear la presencia de estos fármacos en el lugar donde nacen los niños. Además se debe mejorar la estrategia en el terreno, mejorando la captación de mujeres embarazadas sin controles o que abandonan su seguimiento.

Por último, de los ocho niños infectados, uno presentó posible resistencia y otro resistencia a nevirapina. En un caso la mujer había recibido la medicación previo al parto y en el otro caso el niño, causas probables de la aparición de resistencia. La nevirapina se caracteriza por una absorción y distribución rápida seguida de una vida media de eliminación lenta. Una sola dosis oral de $200 \mathrm{mg}$ administrada a la mujer durante el trabajo de parto y una sola dosis administrada al recién nacido a las 48-72 horas después del nacimiento mantiene concentraciones en plasma por encima de $100 \mathrm{microg} / \mathrm{L}$ a lo largo de la primera semana de vida. Esta concentración es diez veces mayor que la dosis in vitro necesaria para alcanzar el 50\% de la concentración inhibidora (IC 50) contra el VIH de tipo silvestre-1. A esta ventaja farmacocinética se contrapone una baja barrera genética, en donde el virus con una única mutación se vuelve resistente en forma rápida a este fármaco en presencia de supresión viral incompleta. Este efecto aparece cuando se utiliza por un tiempo corto, como sucede en la profilaxis ${ }^{(28,29)}$. Para limitar el efecto, se utiliza poco este fármaco en la mujer embarazada previo al parto. Sin embargo, en el recién nacido la situación es diferente, ya que puede evitar la TMI y en caso de infección no figura dentro de los fármacos de primera línea para el tratamiento antirretroviral en este grupo etario.

\section{Conclusiones}

La TMI en los años 2012 a 2014 en usuarias del CHPR fue de $4,2 \%$ y la infección de los niños se asoció con la CV materna ( $9 \%$ en mujeres con CV desconocida o detectable y $0 \%$ en mujeres indetectables). Se registraron ocho niños infectados a predominio de transmisión intraútero. La mayor edad de la mujer, el conocimiento previo al embarazo de la infección y su tratamiento precoz se asociaron con $\mathrm{CV}$ indetectable en la mujer. El protocolo AZT-NVP, última herramienta para disminuir la TMI, no está siendo utilizado en la mitad de los casos por el personal de salud. En este grupo de niños, no se encontró asociación entre infección perinatal y tratamiento incompleto neonatal. De los dos niños con resistencia a los inhibidores no nucleosídicos, una mujer recibió nevirapina en el momento del parto y, en el otro caso, el recién nacido la recibió junto al AZT, causas probables de la aparición de la resistencia.

El conocimiento de la infección, su tratamiento y la CV materna son los responsables más importantes en la TMI. La utilización de ARV durante el embarazo para lograr mujeres con CV indetectable es el objetivo sobre el que debemos seguir trabajando al igual que el cumplimiento de la profilaxis neonatal completa para lograr la eliminación de la TMI del VIH.

\section{Abstract}

Introduction: controlled pregnancy and interruption of breastfeeding are strategies used to reduce vertical transmission of the immunodeficiency virus (HIV). Neonates are subject to prophylactic treatment of zido- 
vudine or combination therapy with zidovudine and nevirapine based on the mother-to-child transmission risk.

Objective: to describe mother-to-child transmission from 2012 to 2014 at the Pereira Rossell Hospital Center, its relationship with the maternal viral load and the observation of the AZT-NVP prophylactic treatment recommended for neonates.

Method: descriptive study, at the Obstetric Pediatrix HIV-Aids Reference Center from September 1, 2012 until December, 31, 2014. The newborns to mother with detectable or undetectable viral loads at the time of delivery. Administration of zidovudine-nevirapine was recorded. Vertical transmission was defined.

Results: 162 women were included in the study, 86 of them with a detectable or unknown viral load and 76 women with a detectable load. The first group gave birth to 88 children and the second one to 76 . Global mother-to-child transmission rate was $4.9 \%, 9 \%$ in the first group and $0 \%$ in the second one. The association between mother-to-child transmission and maternal load was recorded $(\mathrm{P}<0.05)$. Administration of AZT-NVP was indicated in $45.5 \%$ of children. Intrauterine mother-to child transmission was 5 for the 8 infected children. As to the other three children: 2 received AZT and another one received no prophylactic therapy.

Discussion and conclusions: fifty per cent of the women's pregnancies were not dully controlled. Average mother-to-child transmission was $4.9 \%$. Out of the 8 infected cases, 5 happened in the uterus, only an early diagnosis and treatment would have prevented it from happening. The AZT-NVP protocol is not applied in the right way. Its application on the other 3 children may have avoided the infection.

\section{Resumo}

Introdução: o controle da gravidez e a supressão do aleitamento materno são estratégias para diminuir a transmissão vertical (TMI) do Vírus da Imunodeficiência Humana (VIH). No neonato, a profilaxia com zidovudina ou zidovudina com nevirapina é utilizada de acordo com o risco de TMI.

Objetivo: descrever a TMI no período 2012-2014 no CHPR, sua relação com a carga viral materna e o cumprimento da recomendação AZT-NVP no neonato.

Material e métodos: estudo descritivo, realizado no Centro de Referencia Obstétrico- Pediátrico VIH-Sida no período $1^{\circ}$ de setembro de 2012 - 31 de dezembro de 2014. Foram incluídos os recém-nascidos de mulheres com carga viral (CV) detectável ou indetectável no momento do parto. A administração de zidovudina - nevirapina e a transmissão vertical foram registradas.

Resultados: foram incluídas 162 mulheres, 86 com carga viral detectável ou desconhecida e 76 indetectá- vel. As primeiras tiveram 88 filhos e as segundas 76. A TMI global foi de $4,9 \%, 9 \%$ no primeiro grupo e $0 \%$ no segundo. A associação entre TMI e CV materna $(\mathrm{P}<0.05)$ foi registrada. A administração de AZT-NVP foi indicada em $46.5 \%$ das crianças. Nas 8 crianças infectadas, a TMI foi intrauterina em 5 . Nas 3 restantes, duas receberam AZT e a restante não recebeu nenhum tipo de profilaxia.

Discussão e conclusões: a metade das mulheres não controlou sua gravidez adequadamente. A TMI média foi de $4.9 \%$. Das 8 infectadas, 5 foram intrauterinas; somente o diagnóstico e tratamento precoces poderiam ter evitado. O protocolo AZT-NVP, não foi utilizado de forma adequada. É possível que sua aplicação nas 3 crianças restantes tivesse evitado a infecção.

\section{Bibliografía}

1. Connor EM, Sperling RS, Gelber R, Kiselev P, Scott G, O'Sullivan MJ, et al. Reduction of maternal-infant transmission of human immunodeficiency virus type 1 with zidovudine treatment. Pediatric AIDS Clinical Trials Group Protocol 076 Study Group. N Engl J Med 1994; 331(18):1173-80.

Disponible en: http://www.nejm.org/doi/pdf/10.1056/ NEJM199411033311801. [Consulta: abril 2017].

2. McGowan JP, Crane M, Wiznia AA, Blum S. Combination antiretroviral therapy in human immunodeficiency virus-infected pregnant women. Obstet Gynecol 1999; 94(5 Pt 1):641-6.

3. Cooper ER, Charurat M, Mofenson L, Hanson IC, Pitt J, Diaz C, et al. Combination antiretroviral strategies for the treatment of pregnant HIV-1-infected women and prevention of perinatal HIV-1 transmission. J Acquir Immune Defic Syndr 2002; 29(5):484-94.

4. European Collaborative Study. Mother-to-child transmission of HIV infection in the era of highly active antiretroviral therapy. Clin Infect Dis 2005; 40(3):458-65. Disponible en: https://academic.oup.com/cid/article-lookup/doi/10.1086/427287. [Consulta : abril 2017].

5. Tubiana R, Le Chenadec J, Rouzioux C, Mandelbrot L, Hamrene K, Dollfus C, et al. Factors associated with mother-to-child transmission of HIV-1 despite a maternal viral load $<500$ copies/ml at delivery: a case-control study nested in the French perinatal cohort (EPF-ANRS CO1). Clin Infect Dis 2010; 50(4):585-96.

6. Office of AIDS Research Advisory Council. Panel on Treatment of Pregnant Women with HIV Infection and Prevention of Perinatal Transmission. Recommendations for use of antiretroviral drugs in pregnant women with HIV infection and interventions to reduce perinatal HIV transmission in the United States. Rockville, MD: Aidsinfo, 2017. Disponible en: https://aidsinfo.nih.gov/contentfiles/lvguidelines/PerinatalGL.pdf. [Consulta : abril 2017].

7. Uruguay. Ministerio de Salud Pública. Dirección General de la Salud. Departamento de Programación Estratégica en Salud. Área Salud Sexual y Reproductiva. Programa 
Nacional ITS-VIH/Sida. Infección por virus de la Inmunodeficiencia Humana (VIH): pautas para diagnóstico, monitorización y tratamiento antirretroviral. Actualización 2014. Disponible en: http://www.msp.gub.uy/sites/default/files/Pautas\%20VIH\%20para\%20Diagnostico\%20y\%20tratamiento $\% 20$ antiretroviral $\% 20$ adultos-mujeres-ni\%C3\%B1os\%202014.pdf. [Consulta: abril 2017].

8. Townsend CL, Cortina-Borja M, Peckham CS, de Ruiter A, Lyall H, Tookey PA. Low rates of mother-to-child transmission of HIV following effective pregnancy interventions in the United Kingdom and Ireland, 2000-2006. AIDS 2008; 22(8):973-81.

9. España. Ministerio de Sanidad, Servicios Sociales e Igualdad. Secretaría del Plan Nacional sobre el Sida. Sociedad Española de Ginecología y Obstetricia. Sociedad Española de Infectología Pediátrica. Grupo de Estudio de Sida. Documento de consenso para el seguimiento de la infección por el vih en relación con la reproducción, embarazo, parto y profilaxis de la transmisión vertical del niño expuesto. Madrid: MSSSI, 2013.

10. Administración de los Servicios de Salud del Estado. Hospital de la Mujer Dra. Paulina Luisi. Clínicas ginecotológicas A y C. Centro Hospitalario Pereira Rossell. Departamento Obstétrico. Departamento de Emergencia. Departamento de Neonatología. Servicio de Recién Nacidos. Indicadores del Hospital de la Mujer: informe de gestión de maternidad 2013. Montevideo: ASSE, 2013.

11. Uruguay. Ministerio de Salud Pública. Día mundial del VIH/SIDA: $1^{\circ}$ de diciembre de 2015. Informe Epidemiológico VIH/SIDA en Uruguay. Montevideo: MSP, 2015. Disponible en: http://www.msp.gub.uy/sites/default/files/Informe\%20epidemiologico\%20VIH\%202015\%20Uruguay_0.pdf. [Consulta : abril 2017].

12. Gray GE, Urban M, Chersich MF, Bolton C, van Niekerk R, Violari A, et al. A randomized trial of two postexposure prophylaxis regimens to reduce mother-to-child HIV-1 transmission in infants of untreated mothers. AIDS 2005; 19(12):1289-97.

13. Nielsen-Saines K, Watts DH, Veloso VG, Bryson YJ, Joao EC, Pilotto JH, et al. Three postpartum antiretroviral regimens to prevent intrapartum HIV infection. N Engl J Med 2012; 366(25):2368-79. Disponible en: http:/www.nejm.org/doi/ pdf/10.1056/NEJMoa1108275. [Consulta: abril 2017].

14. Pedroso C, Queiroz AT, Alcântara LC, Drexler JF, Diaz RS, Weyll N, et al. High prevalence of primary antiretroviral resistance among HIV-1-infected adults and children in Bahia, a northeast state of Brazil. J Acquir Immune Defic Syndr 2007; 45(2):251-3.

15. Eshleman SH, Hoover DR, Hudelson SE, Chen S, Fiscus SA, Piwowar-Manning E, et al. Development of nevirapine resistance in infants is reduced by use of infant-only single-dose nevirapine plus zidovudine postexposure prophylaxis for the prevention of mother-to-child transmission of HIV-1. J Infect Dis 2006; 193(4):479-81.

16. Mirochnick M, Nielsen-Saines K, Pilotto JH, Pinto J, Jiménez E, Veloso VG, et al. Nevirapine concentrations in newborns receiving an extended prophylactic regimen. J Acquir Immune Defic Syndr 2008; 47(3):334-7.

17. World Health Organization. Consolidated guidelines on the use of antiretroviral drugs for treating and preventing HIV infection: recommendations for a public health approach. Geneva : WHO, 2013. Disponible en: http://www.who.int/hiv/ pub/guidelines/arv2013/download/en/. [Consulta: abril 2017].

18. Office of AIDS Research Advisory Council. Panel on Antiretroviral Therapy and Medical Management of HIV-Infected Children. Guidelines for the use of antiretroviral agents in pediatric HIV infection. Rockville, MD: Aidsinfo, 2017. Disponible en: http://aidsinfo.nih.gov/contentfiles/lvguidelines/pediatricguidelines.pdf. [Consulta: abril 2017].

19. Organización Panamericana de la Salud. Guía práctica para la ejecución de la estrategia y plan de acción para la eliminación de la transmisión materno infantil del VIH y de la sífilis congénita en las Américas. Washington, DC: OPS, 2014.

20. Uruguay. Ministerio de Salud Pública, Dirección General de la Salud. Área de Salud Sexual y Reproductiva. Programa Nacional ITS-VIH/Sida. Guía clínica para la eliminación de la sífilis congénita y transmisión vertical del VIH: Uruguay 2013. Montevideo: MSP, 2013.

21. Ord. No 567. Ref. 001-3-3771/201: test rápidos VIH 2014. Disponible en: http://www.msp.gub.uy/sites/default/files/archivos_adjuntos/Ordenanza\%20test $\% 20$ rapidos\%20vih\%202014.pdf. [Consulta: abril 2017].

22. Rosa MC, Lobato RC, Gonçalves CV, Silva NM, Barral MF, Martinez AM, et al. Evaluation of factors associated with vertical HIV-1 transmission. J Pediatr (Rio J) 2015; 91(6):523-8.

23. Patricio FR, Rutherford GW, Barreto JH, Rodamilans C, Badaró R. Effectiveness of the prevention of mother-to-child HIV transmission in Bahia, Brazil. Braz J Infect Dis 2015; 19(5):538-42.

24. Camacho-González AF, Kingbo MH, Boylan A, Eckard AR, Chahroudi A, Chakraborty R. Missed opportunities for prevention of mother-to-child transmission in the United States. AIDS 2015; 29(12):1511-5.

25. Newell ML. Mechanisms and timing of mother-to-child transmission of HIV-1. AIDS 1998; 12(8):831-7.

26. Uruguay. Ministerio de Salud Pública, Dirección General de la Salud. Áreas Programáticas Salud Sexual y Salud Reproductiva, Salud de la Mujer, ITS-VIH/Sida. Guía clínica para la eliminación de la sífilis congénita y transmisión vertical del VIH. 2 ed. Montevideo: MSP, 2015.

27. Cecchini D, Rodríguez C, Nieto C, Astarita V, Giesolauro R, Martínez M. Prevención de la transmisión vertical del VIH-1 en un hospital público de complejidad terciaria de Buenos Aires, Argentina. Rev Panam Salud Pública 2011; 30(3):189-95.

28. Laurido M. Resistencia del VIH-1 a los antirretrovirales: guía práctica. Buenos Aires: Journal, 2011.

29. Mirochnick M, Clarke DF, Dorenbaum A. Nevirapine: pharmacokinetic considerations in children and pregnant women. Clin Pharmacokinet 2000; 39(4):281-93. 